\title{
Does Aliskiren Protect the Kidney Following Ischemia Reperfusion Injury?
}

\author{
F. T. HAMMAD ${ }^{1}$, S. AL-SALAM ${ }^{2}$, L. LUBBAD ${ }^{1}$ \\ ${ }^{1}$ Department of Surgery and ${ }^{2}$ Department of Pathology, College of Medicine and Health Sciences, \\ United Arab Emirates University, Al Ain, United Arab Emirates
}

Received November 20, 2012

Accepted March 7, 2013

On-line July 17, 2013

\section{Summary}

The effect of blocking the first and rate-limiting step in reninangiotensin cascade on the renal function in ischemia reperfusion injury has not been previously investigated. We investigated the effect of aliskiren, the first approved direct oral renin inhibitor, on the alterations in renal functional parameters in this condition. Wistar rats underwent left renal ischemia for $40 \mathrm{~min}$. Group-1 received normal saline whereas Group-2 received aliskiren ( $30 \mathrm{mg} / \mathrm{kg} /$ day) by gavage for 6 days commencing one day before IRI. The hemodynamic and tubular functions and gene expression of neutrophil gelatinase-associated lipocalin (NGAL) and plasminogen activating inhibitor (PAI-1) in the right and left kidneys were measured five days following the IRI. Comparing Group-1 and Group-2, the left renal blood flow was significantly higher in Group-2 (1.28 \pm 0.36 vs. $0.39 \pm 0.05, \mathrm{P}=0.007)$. Left kidney glomerular filtration rate was also higher in Group-2 but did not reach statistical significance $(0.18 \pm 0.05$ vs. $0.10 \pm 0.02$, $\mathrm{P}=0.07$ ). The left renal $\mathrm{FE}_{\mathrm{Na}}$ was significantly lower in Group-2 (29.9 \pm 6.4 vs. $49.7 \pm 7.8, P=0.03)$. Aliskiren also caused a significant decrease in the gene expression of both NGAL and PAI-1 in the left ischemic kidney. In conclusions, the administration of aliskiren before and after IRI appears to have ameliorated the IRI effect on the total renal artery blood flow, and fractional excretion of sodium and gene expression of both NGAL and PAI-1 indicating a renoprotective effects in IRI.

\section{Key words}

Ischemia-reperfusion injury • Aliskiren • Renal function

\section{Corresponding author}

Fayez T. Hammad, Department of Surgery, College of Medicine and Health Sciences, PO Box 17666, Al Ain, United Arab Emirates. Fax: 009713 7672067. E-mail: fayez@mail2doctor.com

\section{Introduction}

Renal ischemia-reperfusion injury (IRI) is an invariable consequence of several conditions including renal transplantation (Weight et al. 1996). It has been well-established that IRI causes renal functional alterations which might ultimately result in renal impairment (Axelsen and Cartwright 1979, Brady et al. 1996). Several substances have been involved in this process such as the elements of the renin-angiotensin system (RAS) (Kontogiannis and Burns 1998, Hammad et al. 2001, Habibey et al. 2008, Fouad et al. 2010). In this regard, both angiotensin converting enzyme (ACE) inhibitors and angiotensin receptor blockers (ARBs) were shown to ameliorate the ischemia-reperfusion induced renal injury (Habibey et al. 2008, Molinas et al. 2009, Fouad et al. 2010).

The RAS consists of several peptides which interact in a cascade fashion to produce angiotensin II. Renin is the enzyme which is catalyzing the metabolism of angiotensinogen to angiotensin I, which is subsequently converted by the action of ACE to the active hormone angiotensin II. Therefore, the effect of the RAS can be blocked by interrupting this cascade at different levels by agents such as ACE inhibitors and ARBs. RAS blockade can also be achieved by renin inhibitors. Renin inhibition is expected, at least theoretically, to be more effective than the ACE inhibitors or the ARBs in blocking the function of RAS. This is probably due to the fact that renin controls the first and rate-limiting step in RAS. In addition, RAS blockade by ACE inhibitors or by ARBs has been shown to cause a compensatory increase in renin release which might decrease the potential effects of these agents 
(Johnston et al. 1979, Jones et al. 2007). This theoretical effectiveness of renin inhibitors was supported by the findings that the renal vasodilator response to the renin inhibitor enalkiren exceeded the effect of the ACE inhibitor captopril (Cordero et al. 1991, Fisher et al. 1994).

Historically, renin inhibitors have not been clinically successful because of the lack of potency or poor bioavailability. Aliskiren is the first oral direct renin inhibitor which has been approved for the treatment of hypertension by the US Food and Drug Administration. The effect of aliskiren on kidney function in different renal conditions has been studied (Whaley-Connell et al. 2010, Wu et al. 2010, Choi et al. 2011). In IRI, aliskiren has been recently shown to reduce renal fibrosis in a mice model of chronic ischemic kidney injury (Sun et al. 2012). However, the effect of aliskiren on the alterations in renal functional parameters following IRI has not been investigated yet. Thus, the aim of this study was to investigate this effect in a rat model of warm acute IRI.

\section{Materials and Methods}

Studies were performed in male Wistar rats weighing 211-261 $\mathrm{g}$ at the time of IRI. Rats were housed in standard cages and kept in a 12-h light-dark cycle at $20{ }^{\circ} \mathrm{C}$. They were fed a standard rat chow and had free access to water. Animals were fasted for $12 \mathrm{~h}$ before the experimental procedures but had water ad libitum. The experimental protocol was approved by the local animal research ethics committee.

\section{Ischemia-reperfusion injury}

The following procedures were carried out under aseptic conditions. Animals were anesthetized with ketamine hydrochloride (70 $\mathrm{mg} / \mathrm{kg}$, intraperitoneally, Pantex Holland B. V., Holland) and Pentobarbital Sodium (20 mg/kg, intraperitoneally, Sigma Life Science, St Louis, USA). With minimal dissection, the left renal artery was exposed via a flank incision and was occluded using microvascular non-traumatic bulldog clamp. Following a warm ischemia of $40 \mathrm{~min}$, the microvascular clamp was removed to allow reperfusion. At the end, the wound was closed in layers.

\section{Aliskiren/Vehicle administration}

Aliskiren (Novartis Pharma Stein AG, Stein, Basle, Switzerland) was dissolved in $0.5 \mathrm{ml}$ of normal saline and administered by gavage immediately after preparation as single daily dose of $30 \mathrm{mg} / \mathrm{kg}$. Control animals received only $0.5 \mathrm{ml}$ of normal saline. In the two groups, treatment was commenced $24 \mathrm{~h}$ before ischemia and continued daily for 5 days thereafter until the time of the terminal experiment.

\section{Experimental groups}

Animals were randomized into two groups:

1. Group-1 $(n=10)$ : Rats which underwent renal ischemia and received only normal saline.

2. Group-2 $(n=9)$ : Rats which underwent renal ischemia and received aliskiren.

\section{Surgical procedure in the terminal experiment}

All rats underwent terminal experiments five days following IRI. The details of surgical procedure were similar to what has been previously described (Hammad et al. 2012). In brief, after induction of anesthesia and tracheal cannulation, a femoral artery and vein were cannulated. Both kidneys were then exposed through a midline abdominal incision and the upper ureters were cannulated for the collection of urine into pre-weighed micro-capped tubes. The urine volume was determined gravimetrically.

On completion of surgery, rats were infused with a solution composed of fluorescein isothiocyanate-inulin (FITC-inulin, Sigma-Aldrich, St Louis, USA) $(2.5 \mathrm{mg} / \mathrm{ml})$ and para-aminohippuric acid (PAH, SigmaAldrich, St Louis, USA) $(0.2 \% \mathrm{w} / \mathrm{v})$ in $0.9 \%$ saline at a rate of $50 \mathrm{ml} / \mathrm{min}$. A priming dose of $2 \mathrm{ml}$ of the same solution was infused over $2 \mathrm{~min}$. Animals were allowed $2 \mathrm{~h}$ to equilibrate before being subjected to the experimental protocol.

\section{Experimental protocol and assays}

The experimental protocol which consisted of two 30-min clearance periods was similar to what has been described previously (Hammad et al. 2012). The urine and plasma samples were assayed for sodium level and the inulin and PAH contents were determined. The values of Glomerular filtration rate (GFR) and renal blood flow (RBF), urine volume (UV), urinary sodium $\left(\mathrm{U}_{\mathrm{Na}} \mathrm{V}\right)$ and fractional excretion of sodium $\left(\mathrm{FE}_{\mathrm{Na}}\right)$ were calculated as the average of the two clearance periods and were corrected for kidney weight.

\section{Gene expression analysis}

At the end of the experimental protocol, the kidneys were removed. Part of each kidney was excised, immediately snap-frozen in liquid nitrogen and stored at 
$-80{ }^{\circ} \mathrm{C}$ for a later measurement of the relative gene expression of neutrophil gelatinase-associated lipocalin (NGAL) and plasminogen activating inhibitor (PAI-1).

Total RNA was extracted using TRI Reagent ${ }^{\circledR}$ Solution (Life Technologies Corporation, NY, USA) according to the manufacturer protocol. Quality and quantity of the extracted RNA was estimated using NanoDrop instrument (Thermo Fisher Scientific Inc., DE, USA). First-strand cDNAs were prepared in duplicates from $1 \mu \mathrm{g}$ of the extracted RNA using MuLV reverse transcriptase (Applied Biosystems, CA, USA) and served as template for relative gene expression analysis which was also performed in duplicates on ABI-7500 Real Time PCR System (Applied Biosystems, CA, USA) using
TaqMan chemistry. The reaction mixture consisted of 50 ng cDNA, PCR Gold buffer, 0.375 U AmpliTaq Gold DNA polymerase (Applied Biosystems, CA, USA), $\mathrm{MgCl}_{2} 6.0 \mathrm{mM}$, Rox dye $50 \mathrm{nM}$, DMSO $0.4 \%$, Triton X$1000.04 \%$, Nonidet P-40 $0.04 \%$, Tween-20 $0.04 \%$, forward and reverse primers and FAM-BHQ-1 labelled probe (Biosearch Technologies, Inc., CA, USA). Sequences and concentrations of primers and fluorogenic probes are listed in Table-1. Primers and probes were designed using the online RealTimeDesign ${ }^{\mathrm{TM}}$ software (Biosearch Technologies, Inc., CA, USA) in a way that at least one of the primers was spanning an exon-intron junction within their respective gene.

Table 1: Forward and reverse primers and fluorogenic probe sequences used for real time quantitative PCR analysis.

\begin{tabular}{|c|c|c|c|}
\hline Gene & & Sequence & $\begin{array}{c}\text { Concentration } \\
(\mathbf{n M})\end{array}$ \\
\hline \multirow[t]{3}{*}{$R P L P 0$} & Forwad Primer & CAGAGGTGCTGGACATCACAG & 300 \\
\hline & Reverse Primer & CACATTGCGGACACCCTCTAG & 900 \\
\hline & FAM-BHQ-1 Probe & CAGGCCCTGCACACTCGCTTC & 150 \\
\hline \multirow[t]{3}{*}{$P A I-1$} & Forward Primer & GGCACAATCCAACAGAGACAA & 600 \\
\hline & Reverse Primer & GGCTTCTCATCCCACTCTCAAG & 300 \\
\hline & FAM-BHQ-1 Probe & ССТCTTCATGGGCCAGCTGATGG & 150 \\
\hline \multirow[t]{3}{*}{$\operatorname{Lcn} 2(N G A L)$} & Forward Primer & CTGTTCCCACCGACCAATGC & 900 \\
\hline & Reverse Primer & CCACTGCACATCCCAGTCA & 900 \\
\hline & FAM-BHQ-1 Probe & TGACAACTGAACAGACGGTGAGCG & 150 \\
\hline
\end{tabular}

Raw fluorescence data generated by the ABI7500 Real-Time PCR System was subjected to analysis using the Real-time PCR Miner analysis software (Zhao and Fernald 2005). Calculated reaction efficiencies and CTs were then used to calculate the relative gene expression using the delta-delta CT methodology. Results for the gene expression were normalized with $60 \mathrm{~S}$ acidic ribosomal protein P0 gene expression as a house keeping gene.

The results were expressed as the relative gene expression of both NGAL and PAI-1 in the left ischemic kidney compared to the right control kidney in the respective group.

\section{Histological studies}

The right and left kidneys from the two groups (total: 38 kidneys) were fixed in $10 \%$ buffered normal saline, dehydrated in increasing concentrations of ethanol, cleared in xylene and embedded in paraffin. Five $\mu \mathrm{m}$ sections were stained with hematoxylin and eosin. Histological examination and scoring were performed blindly by a pathologist (second author). A numerical score was used to define the degree of tubular cell necrosis as described previously (Mohan et al. 2006) (Score 0: no necrosis; Score 1: few focal necrotic spots; Score 2: tubular necrosis in approximately half of the field; Score 3, tubular necrosis in approximately two thirds of the field; Score 4: approximately the entire field was necrotic). All kidney sections were examined and a numerical score was reported for each kidney. An average score was then calculated for each group. 


\section{Statistical analysis}

Statistical analysis was performed using SPSS V16.0. Results were expressed as means \pm SEM. Oneway factorial ANOVA was used for comparison of variables between the two groups and between the control and ischemic kidneys within each group. $\mathrm{P}$ value of less than 0.05 was considered statistically significant.

\section{Results}

The mean arterial blood pressure $(122 \pm 3$ vs. $121 \pm 3 \mathrm{~mm} \mathrm{Hg}, \mathrm{P}=0.8)$ and heart rate $(455 \pm 10 \mathrm{vs}$. $451 \pm 6$ bpm, $\mathrm{P}=0.7)$ in Group-1 and Group-2 were similar.
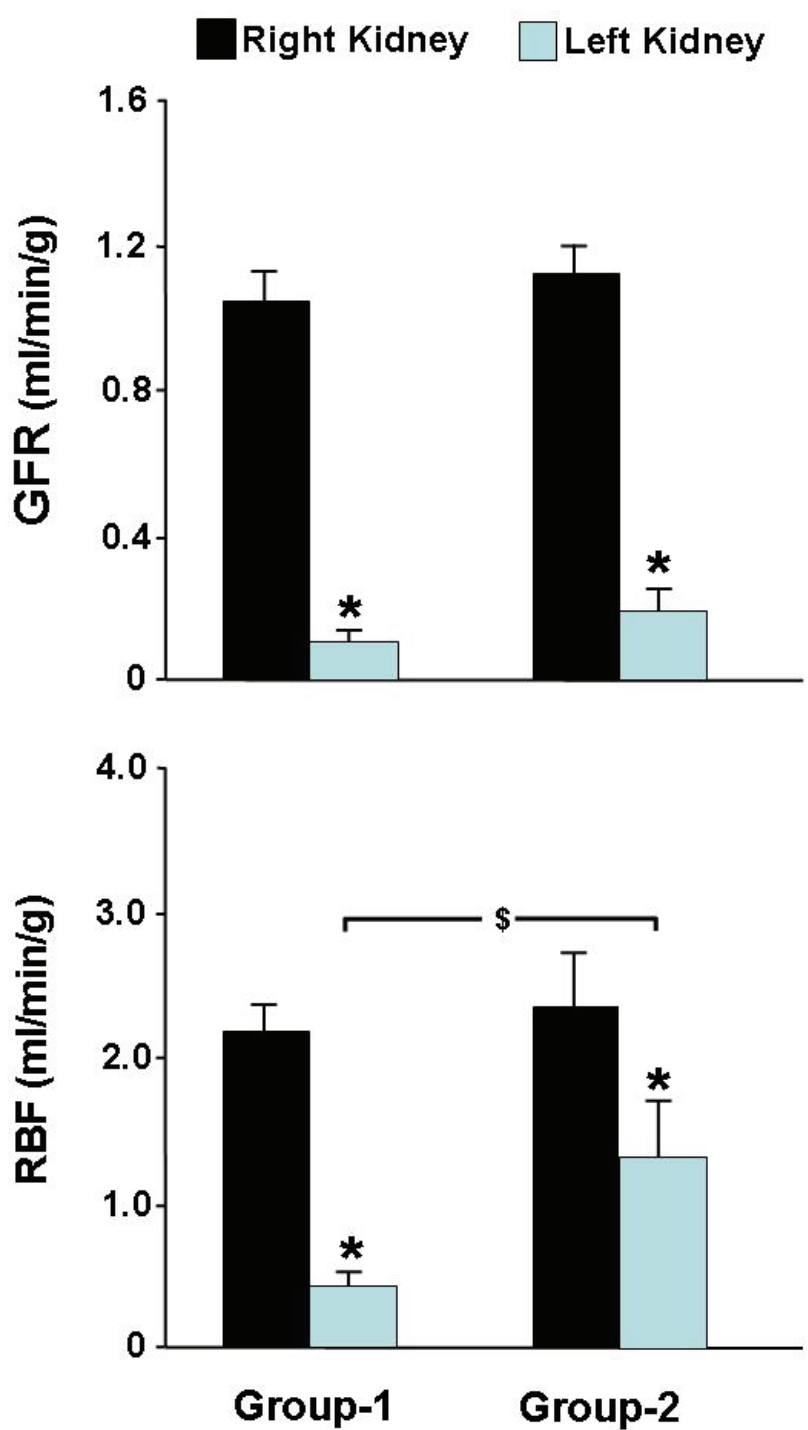

Fig. 1. The glomerular filtration rate (GFR) and renal blood flow (RBF) in the right and left kidneys in Group-1 and Group-2 following $40 \mathrm{~min}$ of left renal ischemia. Values represent mean \pm SEM. * indicates statistical significance between the right and left kidney within the same group whereas $\$$ indicates statistical significance between the left kidneys in both groups.
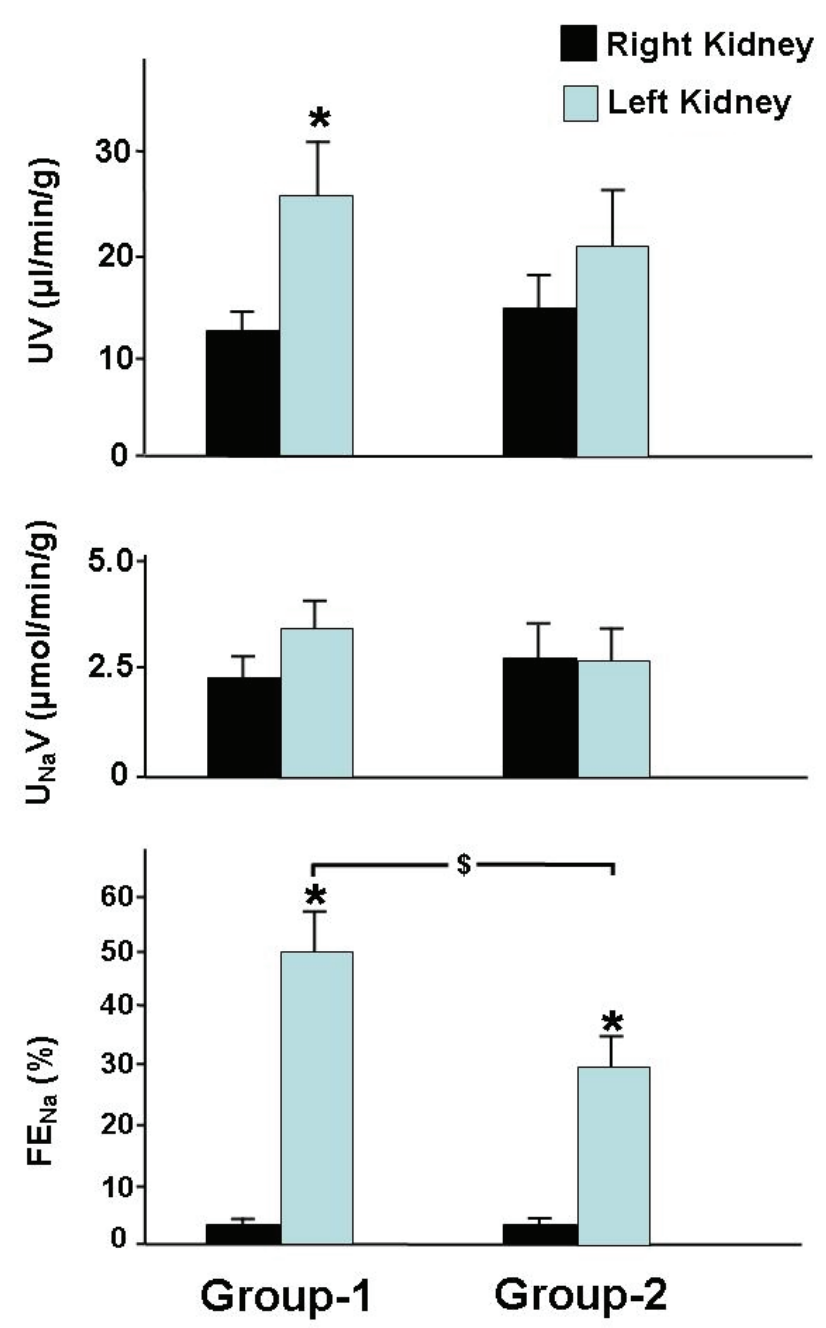

Fig. 2. The tubular functional parameters including urine volume (UV), urinary sodium $\left(\mathrm{U}_{\mathrm{Na}} \mathrm{V}\right)$ and fractional excretion of sodium $\left(\mathrm{FE}_{\mathrm{Na}}\right)$ in both kidneys in Group-1 and Group-2 following left renal ischemia. Values represent mean \pm SEM. * indicates statistical significance between the right and left kidney within the same group whereas ${ }^{\$}$ indicates statistical significance between the left kidneys in both groups.

\section{Glomerular and tubular functions}

In Group-1 which had left renal ischemia but did not receive aliskiren, left $\mathrm{RBF}$, five days following the IRI, was $17 \%$ of the right RBF $(0.39 \pm 0.05$ vs. $2.24 \pm 0.27$ $\mathrm{ml} / \mathrm{min} / \mathrm{g}, \mathrm{P}<0.0001)$. Similarly, the left kidney GFR was $10 \%$ that of the right non-ischemic kidney $(0.10 \pm 0.02$ vs. $1.04 \pm 0.11 \mathrm{ml} / \mathrm{min} / \mathrm{g}, \quad \mathrm{P}<0.0001$ ) (Fig. 1). With the decrease in both RBF and GFR, the UV (26.7 \pm 4.9 vs. $12.3 \pm 1.8 \mu \mathrm{l} / \mathrm{min} / \mathrm{g}, \mathrm{P}=0.006)$ and $\mathrm{FE}_{\mathrm{Na}}(49.7 \pm 7.8 \%$ vs. $2.9 \pm 0.4 \%, \quad \mathrm{P}<0.0001) \quad$ in the left kidney were significantly higher than the right kidney (Fig. 2). $\mathrm{U}_{\mathrm{Na}} \mathrm{V}$ in the left kidneys was also higher than the right one but did not reach statistical significance $(3.5 \pm 0.7$ vs. $2.3 \pm 0.5$ $\mu \mathrm{mol} / \mathrm{min} / \mathrm{g}, \mathrm{P}=0.07)$.

In Group-2 which received aliskiren, the left 
RBF was approximately half of the right RBF $(1.28 \pm 0.36$ vs. $2.39 \pm 0.45 \mathrm{ml} / \mathrm{min} / \mathrm{g}, \mathrm{P}=0.03$ ) and the left renal GFR was $16 \%$ of the right GFR $(0.18 \pm 0.05$ vs. $1.13 \pm 0.09$ $\mathrm{ml} / \mathrm{min} / \mathrm{g}, \mathrm{P}<0.0001$ ) (Fig. 1). As shown in Figure-2, the $\mathrm{UV}$ and $\mathrm{U}_{\mathrm{Na}} \mathrm{V}$ of the left kidney were similar to those from the right kidney $(21.1 \pm 5.7$ vs. $15.2 \pm 3.3 \mu \mathrm{l} / \mathrm{min} / \mathrm{g}$, $\mathrm{P}=0.2$ and $2.6 \pm 0.7$ vs. $2.8 \pm 0.8 \mu \mathrm{mol} / \mathrm{min} / \mathrm{g}, \mathrm{P}=0.4$, respectively) but the left renal $\mathrm{FE}_{\mathrm{Na}}$ was significantly higher than the right kidney $(29.9 \pm 6.4 \%$ vs. $3.1 \pm 0.9 \%$ $(\mathrm{P}=0.001)$.
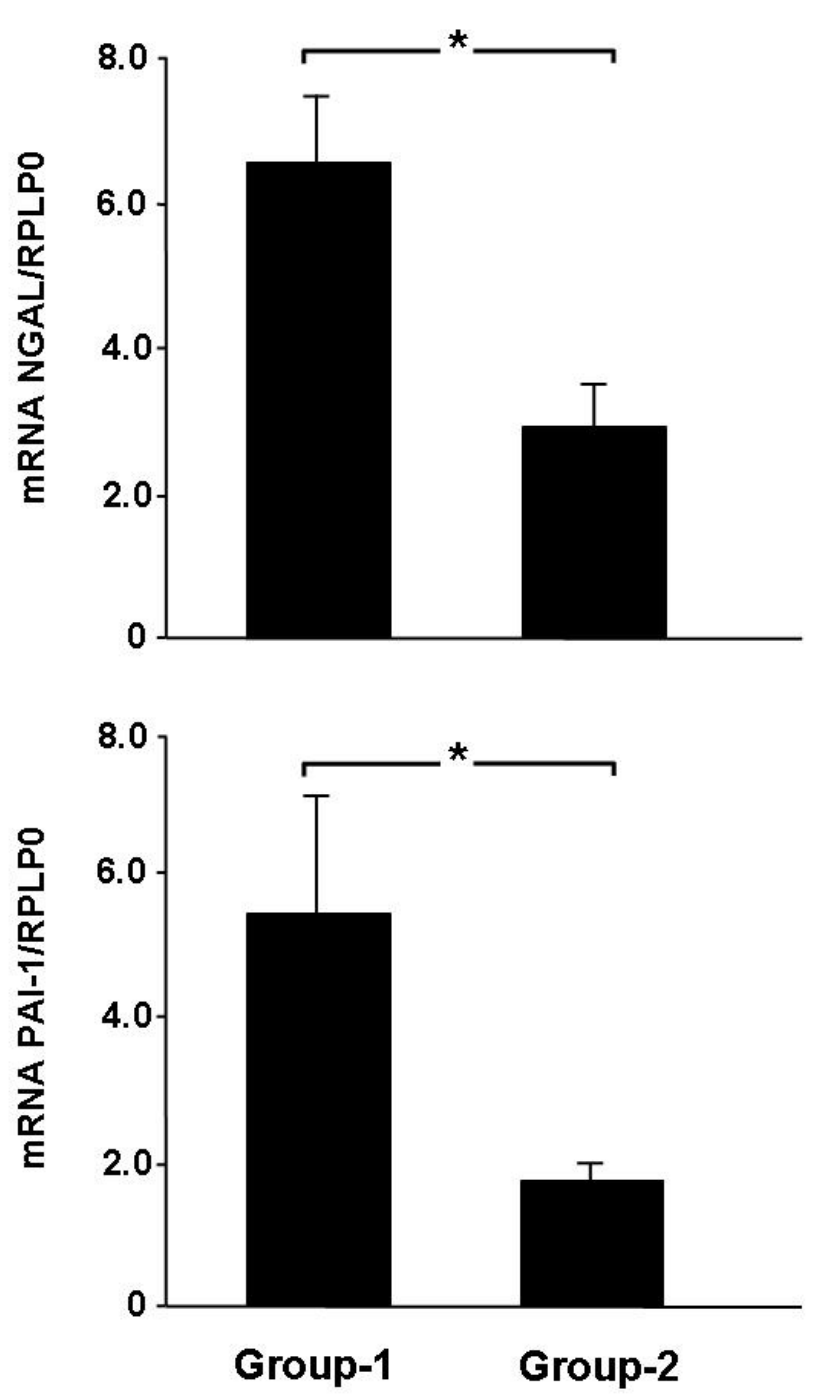

Fig. 3. The expression of NGAL and PAI- 1 genes in Group-1 and Group-2 measured by real time PCR. Results were expressed as the fold increase in the gene expression in the left ischemic kidneys compared to the right non-ischemic kidney in each group. * indicates statistical significance between both groups.

When Group-2 was compared to Group-1, the left RBF was significantly higher in Group-2 (1.28 \pm 0.36 vs. $0.39 \pm 0.05 \mathrm{ml} / \mathrm{min} / \mathrm{g}, \mathrm{P}=0.007)$. The left $\mathrm{GFR}$ was also higher in Group-2 but did not reach statistical significance $(0.18 \pm 0.05$ vs. $0.10 \pm 0.02 \mathrm{ml} / \mathrm{min} / \mathrm{g}, \mathrm{P}=0.07)$ (Fig. 1). As shown in Figure-2, left renal $\mathrm{UV}$ and $\mathrm{U}_{\mathrm{Na}} \mathrm{V}$ were similar in both groups ( $\mathrm{P}>0.05$ for both variables). However, left renal $\mathrm{FE}_{\mathrm{Na}}$ was significantly lower in Group-2 which received aliskiren $(29.9 \pm 6.4 \%$ vs. $49.7 \pm 7.8 \%, \mathrm{P}=0.03$ ) (Fig. 2). All variables in the right kidneys in both groups were similar $(\mathrm{P}>0.05$ for all variables).

\section{Gene expression analysis results}

As demonstrated in Figure 3, there was 6.5 \pm 0.9 fold increase in the expression of NGAL in the left ischemic kidney compared to the right non-ischemic kidney in Group-1 whereas this increase was only $2.9 \pm 0.6$ fold in Group-2 $(\mathrm{P}=0.02)$. Similarly, aliskiren resulted in a significantly lower expression of PAI-1 in the ischemic kidney in Group-2 compared to Group-1 $(1.8 \pm 0.2$ vs. $5.5 \pm 1.6, \mathrm{P}=0.04)$.

\section{Histological studies}

The right non-ischemic kidneys in the two groups had normal architecture (score 0) (Fig. 4). As demonstrated in Figure 3, examination of the left ischemic kidneys in Group-2 has shown a less severe degree of acute tubular necrosis compared to Group-1 despite the fact that when comparing the arithmetic mean histological score of the left ischemic kidneys in the two groups $(2.7 \pm 0.36$ vs. $3.3 \pm 0.23)$, this showed a trend which did not reach statistical significance $(\mathrm{P}=0.09)$. This improvement was demonstrated by the fact that only five animals from group- 2 had a score $\geq 3$ compared to eight animals in Group-1. In addition, none of the animals from Group-1 had a score of 1 whereas there were two animals from Group-2 which had a score of 1 . The number of animals with various scores in both groups were as follows: Group-1: score 4: $n=5$, score $3: n=3$, score 2 : $\mathrm{n}=2$, score $1: \mathrm{n}=0$, score $0: \mathrm{n}=0$ ) and Group-2: score 4: $n=3$, score $3: n=2$, score $2: n=2$, score $1: n=2$, score 0 : $\mathrm{n}=0)$.

\section{Discussion}

In the current study, we have demonstrated for the first time that the administration of aliskiren prior to and following warm renal IRI has resulted in a significant improvement in some of the hemodynamic and tubular renal functional parameters and attenuated the rise in gene expression of some markers of acute kidney injury. 


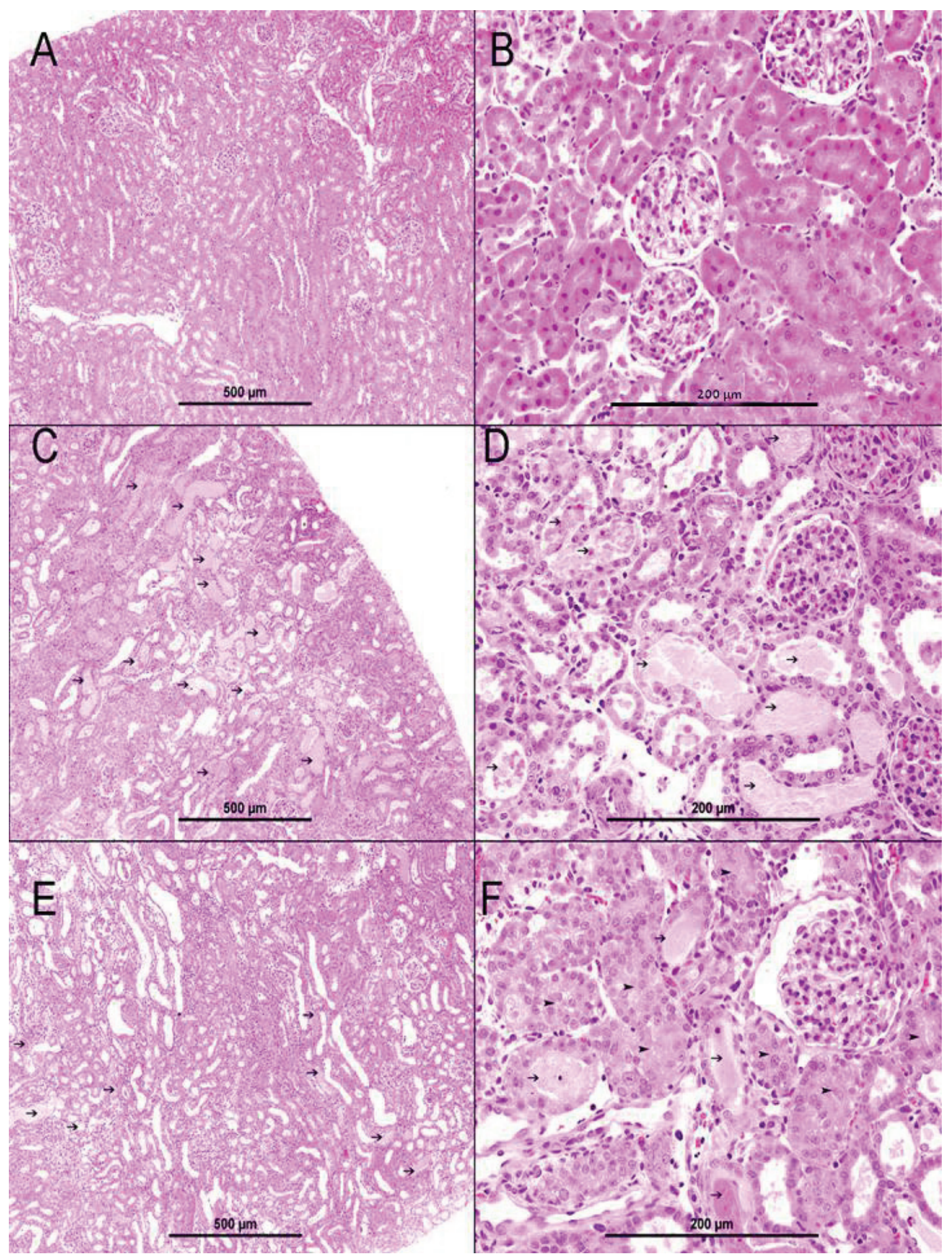

Fig. 4. Light microscopic features of the rats kidney sections (hematoxylin-eosin). A and B: right kidneys showing normal glomeruli and tubules. C and D: left kidneys from group 1 which underwent IRI without aliskiren showing acute tubular necrosis (thin arrows) involving more than $2 / 3$ of renal parenchyma. E: left kidneys from group 2 which underwent IRI and received aliskiren showing improvement of acute tubular necrosis (thin arrows) with involvement half of renal parenchyma. F: left kidneys from group 2 also showing improvement of acute tubular necrosis (thin arrows) with presence of recovered normal renal tubules (arrow head) in some areas.

Renin-angiotensin system (RAS) plays a central role in the development of ischemia-reperfusion induced renal dysfunction. Several studies have shown that RAS blockade by ACE inhibitors or ARBs results in an amelioration of the ischemia-induced renal injury
(Habibey et al. 2008, Molinas et al. 2009, Fouad et al. 2010). Given that renin catalyses the first and ratelimiting step of RAS, direct renin inhibitors were shown to be effective in ameliorating the effects of RAS system in some renal pathophysiological conditions (Whaley- 
Connell et al. 2010, Wu et al. 2010, Choi et al. 2011). In the current study, we have shown that blocking the RAS at its first step using aliskiren results in an attenuation in the ischemia-induced renal injury. Collectively, the data from the current study and from studies which investigated ACE inhibitors and ARBs indicate that blocking RAS at any level would result in an improvement of the ischemia-induced renal functional alterations. However, further studies are required to compare the degree of effectiveness of aliskiren, ACE inhibitors and ARBs in blocking the RAS and IRIassociated renal alterations.

In the current study, aliskiren improved both the $\mathrm{RBF}$ and $\mathrm{FE}_{\mathrm{Na}}$ in the post-ischemic kidney. There was also mild improvement in the GFR although it did not reach statistical significance. The exact reason is difficult to ascertain but it could be due to the possible selective effect of angiotensin II on efferent glomerular arterioles. In this regards, the renin inhibitor aliskiren results in a decrease in the production of angiotensin II. Although angiotensin II causes constriction of both afferent and efferent glomerular arterioles, there is some evidence to suggest that it has a preferential effect on the efferent arterioles which results in the maintaining of GFR especially in pathological conditions (Hall et al. 1977a,b, Edwards 1983). Therefore, decreasing the level of angiotensin II by aliskiren might have resulted in eliminating this effect of selective efferent arteriolar constriction on glomerular filtration and hence a less effect on GFR with aliskiren. However, further studies are required to clarify this point.

In addition to its effect on the hemodynamic renal parameters, the current study indicated that aliskiren significantly reduced the rise in $\mathrm{FE}_{\mathrm{Na}}$ which is caused by the IRI, and hence increased the ability of the kidney to concentrate urine. In this regard, several studies have previously shown that ischemia-reperfusion injury results in tubular damage, at least in the short-term, as indicated by the deterioration of several parameters such as the $\mathrm{FE}_{\mathrm{Na}}$ which reflects the ability of the renal tubules to reabsorb the filtered sodium and hence the concentration ability of the kidney (Hammad et al. 2001, Kiew et al. 2004, Kirkby et al. 2007, Hammad et al. 2012). In the current study, it is unlikely that the improvement in the $\mathrm{FE}_{\mathrm{Na}}$ was due the decline in the production of angiotensin-II as a result of aliskiren administration since angiotensin II is known for its antidiuresis and antinaturesis properties (Hammad et al. 2000). The exact cause for this improvement in the deterioration of the
$\mathrm{FE}_{\mathrm{Na}}$ is difficult to ascertain but could be due the improvement in the degree of tubular necrosis as a result of the improvement in the RBF which was induced by aliskiren administration.

In this model of IRI, measurement of other parameters of tubular damage such as proteinuria would have added to the results. However, in this unilateral renal ischemic model, urine collection in the terminal experiment was performed for a relatively short period using ureteric catheterization, a technique which could have resulted in some degree of trauma to the ureteric wall and would have falsely increased the amount of protein in the collected urine.

In parallel to the improvement in the hemodynamic and tubular functions, there was also attenuation in the rise of both NGAL and PAI-1 in the ischemic kidney in the treated group at the gene expression level. NGAL is one of the acute kidney injury markers and has been shown to increase in IRI. There is an evidence to suggest that it is an important marker in determining the severity and outcome of the injury (Parikh et al. 2010, Mishra et al. 2003). PAI-1 is a fibrogenic factor which has also been implicated in the ischemia-reperfusion induced kidney injury (Favreau et al. 2010). The attenuation of both markers at indicates a protective effect of aliskiren at the gene expression level and more studies are required to investigate the effects of aliskiren on the long-term IRI-induced renal dysfunctions.

In the current study, kidney functions were measured five days following IRI. Early, after the IRI especially in the first $48 \mathrm{~h}$, the GFR would have been minimal after similar periods of ischemia (Sabbatini et al. 2010, Rubinstein et al. 2009). Therefore, it might have been difficult to show any significant effect of aliskiren especially in view of the fact that it would have been administered for only a limited period. Certainly, administering aliskiren for five days following the injury would have given the drug reasonably enough time to exert its action. In the longer-term, despite the recovery of some renal functional parameters such as serum creatinine (Pechman et al. 2009), there is an evidence to suggest that some other renal functional parameters and responses to certain stimuli, might be still altered (Pechman et al. 2009). Further studies are required to investigate the long-term effect of aliskiren on kidney functions.

In the current study, we used a single daily dose of aliskiren. This does not only mimic the clinical setup 
but also is in agreement with animal studies when the drug was also given as a single daily dose and has shown significant effect in different pathological conditions (Singh et al. 2008, Wu et al. 2010, Choi et al. 2011, Rusai et al. 2011). However, the use of aliskiren in renin inhibition in rats might have affected the drug bioavailability. Aliskiren has been shown to have a higher specificity for human and mouse rennin compared to rats (Wood et al. 1987). Ideally, determining a good bioavailability of aliskiren requires measuring plasma rennin activity or angiotensin II levels which was lacking in this study. Nevertheless, the significant effect of aliskiren on the attenuation of the ischemia-induced changes in $\mathrm{RBF}, \mathrm{FE}_{\mathrm{Na}}$ and gene expression of NGAL and PAI-1 indicates that bioavailability was not a very major issue in this study. These findings were generally in agreement with other studies which investigated aliskiren in rats and showed significant effects using similar or even lower doses of aliskiren (Singh et al. 2008, Wu et al. 2010, Tain et al. 2011).

The RBF in the current study is lower than the values obtained in our recent work (Hammad et al. 2012). This might have been due to the fact that a similar rate of para-aminohippuric (PAH) infusion was used in both studies, although the rats used in this study were smaller than those used in our previous work. This might have resulted in some degree of volume expansion in the current study so that the level of PAH in the filtered load could have exceeded the PAH excretion ability by the renal tubules and hence an apparently lower RBF (Tanner and Isenberg 1970, MacDougall and Wiegmann 1988). Higher $\mathrm{FE}_{\mathrm{Na}}$ in both non-ischemic and post-ischemic kidney might support this explanation. Nevertheless, the fact that the same protocol and infusion rate were used in both treated and untreated groups, both of which had an ischemic and non-ischemic kidneys, render it unlikely that this could have affected the overall results.

In conclusion, the administration of aliskiren before and after ischemia-reperfusion injury appears to have a significant protective effect on the total renal blood flow, fractional excretion of sodium and gene expression of both NGAL and PAI-1 indicating a renoprotective effect of this drug in renal ischemiareperfusion injury.

\section{Conflict of Interest}

There is no conflict of interest.

\section{Acknowledgements}

This study was funded by an individual grant from the Faculty of Medicine \& Health Sciences, United Arab Emirates University.

\section{References}

AXELSEN RA, CARTWRIGHT VE: Renal function, cortical blood flow and morphometry in ischaemic acute renal failure in the rat. Pathology 11: 629-640, 1979.

BRADY H, BRENNER B, LIEBERTHAL W: Acute renal failure. In: The Kidney. B. M. BRENNER (ed), W. B. Saunders Company, Philadelphia, 1996, 1201-1252.

CHOI DE, JEONG JY, LIM BJ, CHANG YK, NA KR, SHIN YT, LEE KW: Aliskiren ameliorates renal inflammation and fibrosis induced by unilateral ureteral obstruction in mice. $J$ Urol 186: 694-701, 2011.

CORDERO P, FISHER ND, MOORE TJ, GLEASON R, WILLIAMS GH, HOLLENBERG NK: Renal and endocrine responses to a renin inhibitor, enalkiren, in normal humans. Hypertension 17: 510-516, 1991.

EDWARDS RM: Segmental effects of norepinephrine and angiotensin II on isolated renal microvessels. Am J Physiol 244: F526-F534, 1983.

FAVREAU F, THUILLIER R, CAU J, MILIN S, MANGUY E, MAUCO G, ZHU X, LERMAN LO, HAUET T: Antithrombin therapy during warm ischemia and cold preservation prevents chronic kidney graft fibrosis in a DCD model. Am J Transplant 10: 30-39, 2010.

FISHER ND, ALLAN D, KIFOR I, GABOURY CL, WILLIAMS GH, MOORE TJ, HOLLENBERG NK: Responses to converting enzyme and renin inhibition. Role of angiotensin II in humans. Hypertension 23: 44-51, 1994.

FOUAD AA, QURESHI HA, AL-SULTAN AI, YACOUBI MT, AL-MELHIM WN: Nephroprotective effect of telmisartan in rats with ischemia/reperfusion renal injury. Pharmacology 85: 158-167, 2010.

HABIBEY R, AJAMI M, HESAMI A, PAZOKI-TOROUDI H: The mechanism of preventive effect of captopril on renal ischemia reperfusion injury is independent of ATP dependent potassium channels. Iran Biomed $J 12$ : 241-245, 2008. 
HALL JE, GUYTON AC, COWLEY AW Jr: Dissociation of renal blood flow and filtration rate autoregulation by renin depletion. Am J Physiol 232: F215-F221, 1977a.

HALL JE, GUYTON AC, JACKSON TE, COLEMAN TG, LOHMEIER TE, TRIPPODO NC: Control of glomerular filtration rate by renin-angiotensin system. Am J Physiol 233: F366-F372, 1977b.

HAMMAD FT, WHEATLEY AM, DAVIS G: Long-term renal effects of unilateral ureteral obstruction and the role of endothelin. Kidney Int 58: 242-250, 2000.

HAMMAD FT, WHEATLEY AM, DAVIS G: Role of endothelin ET(A) receptor antagonism in the post-transplant renal response to angiotensin II in the rat. Exp Physiol 86: 365-372, 2001.

HAMMAD FT, AL-SALAM S, LUBBAD L: Curcumin provides incomplete protection of the kidney in ischemia reperfusion injury. Physiol Res 61: 503-511, 2012.

JOHNSTON CI, MILLAR JA, MCGRATH BP, MATTHEWS PG: Long-term effects of captopril (SQ14 225) on blood-pressure and hormone levels in essential hypertension. Lancet 314: 493-496, 1979.

JONES MR, SEALEY JE, LARAGH JH: Effects of angiotensin receptor blockers on ambulatory plasma renin activity in healthy, normal subjects during unrestricted sodium intake. Am J Hypertens 20: 907-916, 2007.

KIEW LV, MUNAVVAR AS, LAW CH, AZIZAN AN, NAZARINA AR, SIDIK K, JOHNS EJ: Effect of antisense oligodeoxynucleotides for ICAM-1 on renal ischaemia-reperfusion injury in the anaesthetised rat. $J$ Physiol 557: 981-989, 2004.

KIRKBY K, BAYLIS C, AGARWAL A, CROKER B, ARCHER L, ADIN C: Intravenous bilirubin provides incomplete protection against renal ischemia-reperfusion injury in vivo. Am J Physiol 292: F888-F894, 2007.

KONTOGIANNIS J, BURNS KD: Role of AT1 angiotensin II receptors in renal ischemic injury. Am J Physiol 274: F79-F90, 1998.

MACDOUGALL ML, WIEGMANN TB: Excretion of para-aminohippurate in the isolated perfused rat kidney: net secretion and net reabsorption. $J$ Physiol 397: 459-469, 1988.

MISHRA J, MA Q, PRADA A, MITSNEFES M, ZAHEDI K, YANG J, BARASCH J, DEVARAJAN P: Identification of neutrophil gelatinase-associated lipocalin as a novel early urinary biomarker for ischemic renal injury. $J A m$ Soc Nephrol 14: 2534-2543, 2003.

MOHAN IK, KHAN M, SHOBHA JC, NAIDU MU, PRAYAG A, KUPPUSAMY P, KUTALA VK: Protection against cisplatin-induced nephrotoxicity by Spirulina in rats. Cancer Chemother Pharmacol 58: 802-808, 2006.

MOLINAS SM, CORTES-GONZALEZ C, GONZALEZ-BOBADILLA Y, MONASTEROLO LA, CRUZ C, ELIAS MM, BOBADILLA NA, TRUMPER L: Effects of losartan pretreatment in an experimental model of ischemic acute kidney injury. Nephron Exp Nephrol 112: e10-e19, 2009.

PARIKH CR, LU JC, COCA SG, DEVARAJAN P: Tubular proteinuria in acute kidney injury: a critical evaluation of current status and future promise. Ann Clin Biochem 47: 301-312, 2010.

PECHMAN KR, DE MIGUEL C, LUND H, LEONARD EC, BASILE DP, MATTSON DL: Recovery from renal ischemia-reperfusion injury is associated with altered renal hemodynamics, blunted pressure natriuresis, and sodium-sensitive hypertension. Am J Physiol 297: R1358-R1363, 2009.

RUBINSTEIN I, ABASSI Z, MILMAN F, OVCHARENKO E, COLEMAN R, WINAVER J, BETTER OS: Hyperbaric oxygen treatment improves GFR in rats with ischaemia/reperfusion renal injury: a possible role for the antioxidant/oxidant balance in the ischaemic kidney. Nephrol Dial Transplant 24: 428-436, 2009.

RUSAI K, SCHMADERER C, HERMANS JJ, LUTZ J, HEEMANN U, BAUMANN M: Direct renin inhibition in a rat model of chronic allograft injury. Transplantation 92: 999-1004, 2011.

SABBATINI M, UCCELLO F, SERIO V, TRONCONE G, VARONE V, ANDREUCCI M, FAGA T, PISANI A: Effects of mycophenolate mofetil on acute ischaemia-reperfusion injury in rats and its consequences in the long term. Nephrol Dial Transplant 25: 1443-1450, 2010.

SINGH VP, LE B, KHODE R, BAKER KM, KUMAR R: Intracellular angiotensin II production in diabetic rats is correlated with cardiomyocyte apoptosis, oxidative stress, and cardiac fibrosis. Diabetes 57: 3297-3306, 2008.

SUN CY, CHERNG WJ, JIAN HZ, HSU HH, WU IW, HSU HJ, WU MS: Aliskiren reduced renal fibrosis in mice with chronic ischemic kidney injury - beyond the direct renin inhibition. Hypertens Res 35: 304-311, 2012.

TAIN YL, HSU CN, LIN CY, HUANG LT, LAU YT: Aliskiren prevents hypertension and reduces asymmetric dimethylarginine in young spontaneously hypertensive rats. Eur J Pharmacol 670: 561-565, 2011. 
TANNER GA, ISENBERG MT: Secretion of p-aminohippurate by rat kidney proximal tubules. Am J Physiol 219: 889892, 1970.

WEIGHT SC, BELL PR, NICHOLSON ML: Renal ischaemia-reperfusion injury. Br J Surg 83: 162-170, 1996.

WHALEY-CONNELL A, NISTALA R, HABIBI J, HAYDEN MR, SCHNEIDER RI, JOHNSON MS, TILMON R, REHMER N, FERRARIO CM, SOWERS JR: Comparative effect of direct renin inhibition and AT1R blockade on glomerular filtration barrier injury in the transgenic Ren2 rat. Am J Physiol 298: F655-F661, 2010.

WOOD JM, STANTON JL, HOFBAUER KG: Inhibitors of renin as potential therapeutic agents. $J$ Enzyme Inhib $\mathbf{1}$ : 169-185, 1987.

WU WP, CHANG CH, CHIU YT, KU CL, WEN MC, SHU KH, WU MJ: A reduction of unilateral ureteral obstruction-induced renal fibrosis by a therapy combining valsartan with aliskiren. Am J Physiol 299: F929F941, 2010.

ZHAO S, FERNALD RD: Comprehensive algorithm for quantitative real-time polymerase chain reaction. $J$ Comput Biol 12: 1047-1064, 2005. 